\title{
Article
}

\section{Investment Models for Enterprise Architecture (EA) and IT Architecture Projects within the Open Innovation Concept}

\author{
Igor V. Ilin ${ }^{1}$, Anastasia I. Levina ${ }^{1, *}$, Alissa S. Dubgorn ${ }^{1}$ and Alain Abran ${ }^{2}$ D \\ 1 Institute of Industrial Management, Economics and Trade, Peter the Great St. Petersburg Polytechnic \\ University, 195251 Saint Petersburg, Russia; igor.ilin@spbstu.ru (I.V.I.); dubgorn@spbstu.ru (A.S.D.) \\ 2 Department of Software Engineering and Information Technologies, École de technologie supérieure, \\ Université du Québec, Montréal, QC H3C 1K3, Canada; alain.abran@etsmtl.ca \\ * Correspondence: levina_ai@spbstu.ru
}

Citation: Ilin, I.V.; Levina, A.I.; Dubgorn, A.S.; Abran, A. Investment Models for Enterprise Architecture (EA) and IT Architecture Projects within the Open Innovation Concept. J. Open Innov. Technol. Mark. Complex. 2021, 7, 69. https://doi.org/10.3390/ joitmc7010069

Received: 14 January 2021

Accepted: 17 February 2021

Published: 20 February 2021

Publisher's Note: MDPI stays neutral with regard to jurisdictional claims in published maps and institutional affiliations.

Copyright: (C) 2021 by the authors. Licensee MDPI, Basel, Switzerland. This article is an open access article distributed under the terms and conditions of the Creative Commons Attribution (CC BY) license (https:// creativecommons.org/licenses/by/ $4.0 /)$

\begin{abstract}
Information technologies (IT) architecture and infrastructure is a significant cost item, especially for enterprises with complex production infrastructure and equipment that require automated and digital devices to collect and process primary data on technological and production processes. Most investment models for enterprise-wide development projects usually do not take into account the automation's costs, including the design and implementation of information systems. The Enterprise Architecture (EA) paradigm has been proposed to bridge the gap between the business and the IT sector. The study aims to develop investment models for projects for the implementation and development of EA solutions, including IT architectures that eliminate the shortcomings of existing approaches. The research methodology is based on the analysis of published approaches to investment models for projects creating and developing EA, IT architectures with the identification of their advantages and limitations, and on the analysis of IT investment assessment practices in Russian infrastructure-intensive companies. As a result, investment and appraisal models are proposed that have advantages associated with the ability to calculate the effect of an integrated approach to the implementation of IT solutions, a more accurate calculation of an investment project cost by taking into account the IT system's cost, a reduction in the investment cycle of development and implementation of architectural solutions, including physical and IT component.
\end{abstract}

Keywords: investment models; IT architecture design; enterprise architecture (EA); COSMICISO 19761

\section{Introduction}

It is hard to imagine a modern organization doing without information technologies (IT) and digital technologies. Furthermore, as the scale of business operations and data processing increases, IT plays an increasingly important role in ensuring business efficiency. Nowadays, the conditions for running a business are exceptionally dynamic with the rapid advancement of technologies, digital environments, and related marketing and logistics technologies causing significant concurrent changes in the patterns of supply and demand, pricing, and market trends [1]. These dynamically evolving conditions in external environments require greater business agility. Therefore, providing prompt responses and reforming the inner infrastructure when facing external challenges are key factors of competitiveness and long-term efficiency.

The study reported here focuses on investment models for integral automation projects and the creation of individual IT infrastructure items in the context of ongoing digital transformation. One of the important features of the digital transformation (in particular in manufacturing-with the Industry 4.0 concepts) is the integration of information technologies (IT) and operations technologies [2]. This is a topical issue for organizations with automated equipment for collecting and processing data. Large industrial enterprises, utility providers, transportation and urban infrastructure organizations, the defense 
industry, and other sectors need complex production infrastructures for implementing technologies that help carry out their main activities. Their operational infrastructures, as part of the information exchange processes of the organization, collect a great deal of primary data on the implementation of processes. Such enterprises are the main object of this study and will be referred to hereafter as infrastructure-intensive enterprises, a term first introduced by Levina, Borremans, and Burmistrov [3]. Infrastructure-intensive enterprises are supposed to be inclined to active innovation implementation, as modern technologies (operational, information, management) are changing fast and the competitive advantage belongs to those who can effectively and smoothly implement innovations into their processes and products.

Forecasting investment decisions for information systems and technologies has been a challenging issue for academia and professional communities since the beginning of active automation of business, engineering, and production processes. Information technologies (IT) are rarely the primary cause of success and efficiency improvements in business activities. However, the adoption of particular technologies, tailored to meet the strategic business goals, can speed up the achievement of concrete results and improvements in business activities in general. When put to good use, IT can be the enabler of business growth.

The enterprise architecture (EA) paradigm was proposed initially in 1987 to manage technologies and adjust them to business needs. EA has since been adopted as a means of deploying technological changes and bridging the gap between businesses and the IT sector. In the early years of EA studies, the emphasis was placed on understanding EA architecture and its advantages for businesses [4]. The expectations in the literature were that EA would foster better decision making, cut IT spending, improve business processes, and allow more efficient utilization of resources.

Various authors [5-14] have pointed out multiple benefits expected from the EA approach to engineering business operations, such as

- Evolution-based development and management of business architecture;

- An integral picture of the enterprise;

- Higher capitalization of the enterprise;

- Harmonization of operating activities and IT with the business strategy;

- Improved coordination of activities with business partners;

- Customer-centered orientation;

- Improved and standardized business processes, harmonization (leveling) of business operations and IT;

- Greater efficiency of using data and information, more effective decision making;

- Improved innovation management, risk management, personnel management, asset management, change management;

- Improved IT investment management and more opportunities for replicating and scaling architectural solutions;

- More efficient operating activities, significant quality improvements, more stable business operations, cost savings, shorter solution adoption, and product manufacturing cycles.

The ability of organizations to transform and to innovate is an essential capability in a competitive market [15]. Both innovations and transformations mean implementing changes in a company. If a company professes open innovation philosophy, then its internal structure should be adapted to constant change management, i.e., must be transparent, well-structured, ready for reengineering. The intent of an EA is to determine how an organization can most effectively achieve its target future state. We consider the EA one of the important prerequisites for innovative companies, especially those where operational technologies imply complex technological innovations. For such types of companies innovations can come from all the layers of the EA: business innovations, IT innovations, operational technology innovations [16-20]. The EA model should give a clear vision of the interconnection and interrelationship of all mentioned aspects in order to run innovation implementation smoothly and effectively. 
In our opinion, the main effect of developing and adopting EA, and its elements (including IT), is that business operations become more transparent and business reengineering more agile:

1. The transparency of operations ensured by the business architecture model allows both efficient management of the organization, in the short run, and timely reaction to changes in the external environment by restructuring its activities;

2. The agility provided by EA makes it possible for the organization to shift smoothly and effectively from one technology to another, from one business model to a new one.

In addition, the design and development of the enterprise's architecture allow timely discovery of potential bottlenecks in the management systems and elimination of inefficiency factors upfront in the business design phase by adopting efficient models of practice.

Organizations need to forecast the investments required for adopting the EA paradigm and, when planning EA investments, need to have the analytical tools to calculate and quantitatively forecast both the investment costs and the EA benefits hoped for $[14,21,22]$.

The first aspect of the EA and IT project investment calculation is that, as the implementation of EA elements typically leads to large re-engineering projects that require significant investments, they do not seem attractive in the short term, since traditional investment models for assessing both revenues and costs of a project do not take into account the real effect of the EA paradigm enterprise-wide. Furthermore, while the available investment models for creating an enterprise and its parts include the costs of creating the physical infrastructure related to the primary activity technology, they typically ignore the automation-related costs.

In terms of the absolute size of IT budgets of modern businesses, IT architecture and infrastructure are very expensive business items and require separate creation and maintenance planning. This is especially relevant for enterprises with a complex production infrastructure (including items such as buildings, structures, equipment, machinery) requiring automatic controls or digital devices for collecting and processing primary data on engineering and production processes. These infrastructure items are full-fledged participants in the enterprise's information exchange. In these cases, the costs of creating the IT architecture and supporting infrastructure needs to be distributed among a number of areas such as

- Supervisory control and data acquisition (SCADA) systems;

- Management information systems (MIS);

- Enterprise resource planning (ERP);

- Business intelligence (BI) systems;

- Information technologies;

- Infrastructure (communication, control, and automation shops, in-house personnel, labs, services, etc.).

For example, the Russian reference books on benchmark prices for construction design (issued in 2002 and updated yearly) [23] include the elaboration of the AUTOMATION section specifically for electric control and instrumentation (EC\&A) (i.e., bottom-level automation). However, when a customer and a contractor estimate design costs based on these benchmark reference books, the overall cost of work will cover only the scope related to elaborating the design documents for construction and not the necessary IT automation systems.

In addition, the investment cycle for creating an enterprise with a complex production infrastructure may take many years; similarly, the creation of functional IT architecture at such facilities may take considerable time as well. The EA methodology for the complex design of the EA and all of its items includes, particularly but not exclusively, the synchronized design and creation of both the physical infrastructure and the IT architecture items in order to shorten the investment cycle through parallel work delivery.

The scope of work within the Russian benchmark reference books does not include the cost of elaborating the engineering documents for automated systems and information 
technologies: the cost of these works are considered separately. The calculation of the costs of a full-fledged IT architecture design is a distinct and additional task. As a result, the investment costs of creating IT architecture and infrastructure for deployment and operation have not traditionally been included in enterprise creation costs. This could explain why project capital outlays in infrastructure-intensive enterprises are frequently underestimated in Russia, and most probably elsewhere as well.

The calculation and forecasting of IT investments in monetary terms have been a matter of debate since their origin. This issue must be considered as well from the point of view of long-term efficiency and a time frame of expenses and benefits. Integral IT architecture design, adoption, and development projects have strategic value for all organizations. Related decisions must be made by the business owners and top management because they are the target beneficiaries of these large-scale projects. In this respect, it is important to use investment models, measures, and criteria intelligible at this management level, that are aligned with the goals and objectives of this level of the business hierarchy.

This study proposes investment models for projects adopting and developing EA solutions that include IT architectures. The investment and assessment models proposed here address a number of the weaknesses of existing investment and assessment approaches.

More specifically, this study proposes investment models to tackle four challenges:

1. Forecasting investments for integral IT architecture design and implementation projects to make automation projects more efficient by ensuring the integrity of the created architectural model;

2. More precise investment and assessment models of enterprise creation project cost by including IT costs;

3. Shortening the investment cycle of putting created/upgraded works into operation by synchronizing the creation of an enterprise with its IT architecture;

4. The operationalization of these IT inclusive investment models through adequate quantitative software-specific measures.

The rest of the paper is structured as follows: Section 2 presents related works and their limitations. Section 3 details the proposed investment models. Section 4 discusses the quantitative tools identified for operationalizing the proposed investment models. Section 5 summarizes the work and suggests future studies.

\section{Related Work}

This section analyzes published approaches to investment models for projects creating and developing EA and IT architectures and related items, identifying their advantages and limitations. This allows us to identify the underlying methodologies for project investment models based on applying the EA approach to business engineering.

A number of studies examined the quantification of the effects of applying the architectural approach, in particular for developing and adopting IT solutions [4,24-33]. All of these studies conclude that EA is of major value for organizations and helps them achieve their business goals by harmonizing IT initiatives with business tasks. Nonetheless, despite several proposals measuring the effect of applying the EA approach, there are few studies that confirm concrete achievements in this area.

Kurek, Johnson, and Mulder [29] attempted to quantitatively determine, from different viewpoints, the EA value of IT projects. Comparing IT projects implemented with and without the architectural approach, they reported that when the EA approach was applied the failure rate was lowered by $26 \%$.

In addition to the literature on the efficiency of the adoption and implementation of EA projects, our research team also held discussions with experts in business and industry automation to discuss investment models used in industry as well as to clarify their needs for measuring the effects of applying the EA approach that includes IT projects.

From the related works and discussions with the industry, the following approaches to forecast and assess the efficiency of EA development projects, including IT architecture automation and re-engineering, have been identified: 
1. Total Cost of Ownership-TCO;

2. Internal business efficiency-Cost-Effectiveness Analysis (CEA): cutting costs of business processes including automation and optimization;

3. External efficiency: expanding the market share and penetrating new markets through efficient marketing and logistics;

4. Overall business value: increasing business value through the availability of an efficient IT infrastructure.

Quantitative efficiency models of investments in IT remain a matter of debate ever since their emergence. It is obvious that for EA and IT infrastructures the parameters required are long-term efficiency and changes in operational costs and benefits over time.

Integral IT infrastructure development, adoption, and upgrade projects have strategic value for organizations. Furthermore, the decisions to implement such projects are made by business owners, the ultimate beneficiaries of these EA projects. In this respect, it is important to use efficiency indices understandable at this level of administration and commensurate with the goals and objectives of this level of business administration.

Each of the above approaches for investment models and performance assessment of projects adopting and upgrading architectural solutions (including IT infrastructure) are described in the following subsections.

\section{Theoretical Background}

\subsection{Total Cost of Ownership (TCO)}

Total cost of ownership (TCO) is a financial model for calculating the direct and indirect costs of a product or system, including the costs of owning an IT system. The TCO model relies on the full costing concept according to the principles of management accounting. It includes the total cost of buying, servicing, modernizing, and disposing parts of the computing equipment throughout its entire service life [34,35].

Originally developed by Gartner Inc. in 1986 for personal computers, the TCO concept was then extended to all aspects of grid computing, including software, servers, and mainframes. Gartner defines TCO as a comprehensive assessment over time of information technologies and other costs at the enterprise level. TCO for IT includes buying hardware and software, management and support, communication, end-user expenses, and alternative expenses, such as idle periods, training, and other productivity losses [36]. Since the efficiency of investing in IT is currently a topical business issue for the TCO concept, it is very popular.

Among the weaknesses of the method, it is reported that TCO can only be used for cost-cutting [37] and does not permit measuring or maximizing the benefits. For example, TCO is often used for benchmarking, i.e., comparing enterprise performance with that of its rivals and other representatives of the sector. Furthermore, even when an IT product has a low cost of ownership, this does not help to forecast or characterize in any manner the quality of its services and the experience of using it. In addition, the TCO model does not include several hidden costs of owning IT (e.g., training new users when connecting new worksites and familiarizing users to the system).

The TCO model authors recognized early that it was not comprehensive and later proposed a number of upgrades. For instance, adding a so-called 'complexity index' in an attempt to take into account the kind of work done using IT. For example, the cost of owning IT for one worksite per time period compared with the earnings from this worksite. This adaptation of the model is reasonable when it is easy to calculate the earnings from a specific employee, but the calculations are more complicated when the earnings from a particular worksite are not obvious and not easily quantifiable.

In summary, the TCO model applies to cost forecasting and assessment of the amount an enterprise must spend on owning IT with the condition that all the formative factors of the cost of ownership are taken into account. The consideration of all the indices implies certain difficulties in collecting the necessary data. Thus, some of the factors forming the cost of owning IT need to be distinguished: 
(a) Explicit factors: such as hardware, license buying, and license payments, personnel, expenses on the adoption of software and equipment, maintenance and support, development of user apps, upgrading, and power supply;

(b) Indirect factors: such as system idle periods in terms of lost opportunities and capacity, territorial attachment, changes in platforms and technology, availability of nonstandard configurations, and training of new users.

\subsection{Total Value of Ownership (TVO)}

To obtain a more integrated forecast and assessment of IT investments, it is necessary to compare TCO values with their performance by tracking specific IT costs in real-time mode. The index proposed for this purpose specifically for IT projects is the 'Total value of ownership' (TVO) model [38]. The TVO model forecasts and assesses both the costs and benefits of adopting information systems and technologies. TVO characterizes more completely the economic results of adopting IT.

However, this investment and assessment model is fairly information intensive. The information necessary for determining the TVO may be unavailable or partially available, which is why the use of this model is often not feasible in practice. Another highlighted difficulty is the complexity of integrating data collection with existing control processes.

\subsection{Internal Business Efficiency: Cost Effectiveness Analysis (CEA)}

The calculation of internal business efficiency by assessing business processes is referred to as cost effectiveness analysis (CEA): a tool for assessing the prime cost of making a product or rendering a service by managing processes producing such a product or rendering a service [39-41]. While conventional financial methods of cost accounting are used to forecast and assess corporate activities by functional operations rather than by concrete products (services) provided to the customer, CEA works differently. Since the manufacture of products and the rendering of services require executing certain processes and consuming a certain amount of resources, the expenses of executing a process are calculated by transferring the resource costs to the process steps costs. As a result, the prime cost of a product or service consists of the overall cost of executing all the related processes. Whereas conventional methods calculate expenses on some activities only by their categories, CEA shows the cost of executing all the steps in a process. Thus, CEA is the most precise way of defining the expenses on product manufacturing (or service delivery) and also provides information for analyzing and improving business processes.

Automation as one of the ways of executing individual processes also affects the cost of individual process steps:

- On the one hand, automation lowers the process costs by cutting their execution time and consumption of particular resources (for example, manpower and hard-copy paperwork), as well as improving the precision of decision making;

- On the other hand, automation transfers the cost of using IT to the process cost;

- The traditional limitations of CEA include:

- An expensive and highly complex collection of the data necessary for cost assessment of the process steps. This is especially true for management processes where the main part of the cost structure is staff working hours. Since decisions on integrating information systems are mostly related to changing management processes, this flaw affects the application of CEA for assessing the efficiency of projects for developing IT architecture and its elements;

- Consideration of permanent costs as a variable. Similar to other approaches of transferring costs to their origin centers (processes, products, services), CEA treats fixed costs as if they were variable and, therefore, provides an inaccurate picture that may lead to wrong decisions. Thus, the transfer of the IT system cost to individual processes may lead to a refusal to implement them, even though this refusal will negatively affect the business in general;

- The difficulty of the allocation of the overhead costs to the process steps; 
- The approach helps calculate each process cost, but it is difficult to determine the automation impact on the process cost, and especially difficult to evaluate the cost and cost effectiveness of integrated process automation.

In summary, CEA provides a clearer and more informative picture for analyzing and enhancing each particular process and particular process steps, but is labor-intensive and not always informative for forecasting and assessing integrated business automation projects.

The approach required according to our goals must target forecasting the performance of the business as a whole, not only its processes.

\subsection{Business Value}

The concept of the business value is based on assessing the forecasted growth of the business value with the implementation of particular projects [9,42-44]. It developed as part of criticizing the approach to assessing investment projects against the profit maximization criterion, which often fails to provide a positive result for particular projects because it ignores the non-monetary components. The investments in EA increase current permanent or variable costs, which negatively affect an organization's profitability in the short run. This then requires assessing architectural solutions for efficiency by another approach, for instance, one based on assessing the impact of reorganizing a company through its business value increment.

The application of business value to assessing managerial solutions for efficiency is justified by criteria such as

1. The quality of key task performance. Although delegated to the company managers, it is defined by the business owners and the most informative performance indicator for them is the prosperity of the organization, i.e., increase of the business value;

2. The traditional enterprise cost-effectiveness indices (net surplus, operational margin, etc.), as well as economic efficiency indices of investment projects (net present value, payback time), do not allow adequate assessments of the effect of strategic managerial decisions in the long run. The recommended index of the long-term financial effect of investments or managerial decisions is business value;

3. Assessment centered on profit improvements ignores working conditions and other non-monetary factors that may have no negative effect on operating profits but may have a potentially negative effect on future activities.

There are various approaches that help evaluate actual business value:

- Discounted cash flow (DCF, NPV): this model is broadly used in practice because it is based on inbound and outbound cash flows, not on accounting income. This parameter is informative for strategic analysis but is not fit for historical evaluation. At the same time, this model is based on a historical evaluation for the return on investment (ROI) through the weighted average capital cost (WACC). This index must be enriched with strategic and operational factors of business value;

- Economic profits: this model helps to determine whether the company generates enough profit for reimbursing its capital cost. Similar to the first model, it takes into account future operating income flows against the weighted average capital cost (WACC);

- $\quad$ Adjusted present value (APV): this model is calculated as the discounted cash flow but on the assumption that the project is fully paid for by means of the organization's funds, which mainly carries tax benefits;

- Free cash flow on equity (FCFE): this model shows the cash flows that can be distributed as dividends among the shareholders after all expenses and reinvestments are made and debts paid. While the dividends are the cash flows paid to the shareholders, the FCFE is the cash flow available to them. It is usually calculated as part of the DCF evaluation. This index is rarely used for business assessment because in this model the operating performance and the structure of capital in the cash flow are mixed, which may lead to errors in business value assessment [45]. 
None of the mentioned parameters is fully informative per se. They do not give a clear picture of real performance (e.g., they describe only the revenue or cost aspect of performance) and require additional explanatory factors or indicators.

\section{Results}

This section details the approaches proposed in this study for the forecasting, and later assessment, of IT architecture design projects as part of creating and developing EA to achieve three major objectives:

- Integral IT architecture design and implementation project assessment: making automation projects more efficient by ensuring the integrity of the created architectural model;

- More precise investment and assessment models of enterprise creation projects costs by including IT costs;

- Shortening the investment cycle of putting created/upgraded works into operation by synchronizing the creation of an enterprise with its IT architecture.

\subsection{Investment Model for Integral IT Architecture Design and Implementation Projects}

The approach proposed for forecasting the effect on projects adopting IT architecture and its components relies on integrated business automation, especially in the initial phase of enterprise creation. We claim that it is more efficient than re-engineering and integration of active information systems during operation. The benefits are achieved through the integration of the created architectural model, where all the components are designed as parts of a single system compatible with each other in advance.

For comparison purposes, two alternatives are discussed:

(a) Integrated investment model: the IS hardware and software systems are developed as an integrated whole in the initial phase of enterprise creation, interoperability information systems are chosen, and adoption is implemented at once or in phases according to the integrated project;

(b) Patchwork investment model: the same IS hardware and software systems are designed and developed not as an integrated whole, but piecewise leading to patchwork automation of particular areas of activity executed at different times, with different technologies and distinct business objectives.

\subsubsection{Integrated Investment Model $C_{I T}^{1}$}

Within the context of integrated automation in the enterprise creation phase, the integrated costs of IT architecture (even when the expenses are incurred at different times) can then be calculated according to

$$
C_{I T}^{1}=\sum_{i=1}^{n} C_{I S_{i}}+\sum_{j=1}^{m} C_{i n f r_{j}}
$$

where:

- $C_{I T}^{1}$ is the aggregate cost of creating the IT architecture and its supporting IT infrastructure;

- $C_{I S_{i}}$ is the cost of developing subsystem $i$ of the IT architecture;

- $C_{i n f r_{j}}$ is the cost of developing component $j$ of the IT infrastructure.

\subsubsection{Patchwork Investment Model $C_{I T}^{2}$}

In the absence of an initial plan for integral automation (e.g., within a patchwork automation approach), the cost of re-engineering existent IT architecture (apart from the costs mentioned in Equation (1)) would include such additional components as

(a) The cost of integrating (upgrading) the systems or ensuring the exchange of information among them, including the cost of re-engineering the existing IT infrastructure; 
(b) Alternative costs related to adopting information systems within an ongoing operational enterprise (e.g., idle period losses at particular work areas or need for using two information systems in parallel when switching from one to the other).

In this case, the costs without discounting are given by

$$
C_{I T}^{2}=\sum_{i=1}^{n} C_{I S_{i}}+\sum_{j=1}^{m} C_{i n f r_{j}}+c_{i n t}+c_{\text {alter }}
$$

where:

- $C_{I T}^{2}$ is the aggregate cost of creating the IT architecture and its supporting IT infrastructure;

- $C_{I S_{i}}$ is the cost of developing subsystem $i$ of the IT architecture;

- $\quad C_{i n f r_{j}}$ is the cost of developing component $j$ of the IT infrastructure;

- $\quad c_{\text {int }}$ is the additional cost of information system integration, including the need for new IT infrastructure objects (capacities);

- $\quad c_{\text {alter }}$ is the alternative cost related to adopting information systems within an ongoing operational enterprise.

From the above, the costs of patchwork automation are of course higher than when automation is deployed in an integrated manner:

$$
C_{I T}^{2}>C_{I T}^{1} .
$$

In addition, projects funded from the development budget and classified as investments are the ones that allow enterprises to gain financial advantages or cut costs. As a rule, the strong points of such projects are assessed against the criterion of return on investment (ROI).

The incorporation of IT costs into the costs of an investment project is also important in terms of taxation. If the project is funded using a bank loan, the interest paid out is classified as operating expenses and, therefore, lowers the taxable profit. In contrast, when the adoption of IT architecture elements is funded from operating revenues while running the business, the expenses do not lower the taxable profit.

\subsection{More Precise EA Project Investment and Assessment Model}

To address the problem of a more precise EA project investment and assessment model which includes the costs of automation the following simple model is proposed.

First, to determine a range of automation costs in enterprises with production operations equipped with automated production infrastructure facilities (e.g., mining, petroleum and gas production, machine building, metallurgical industries, marine and transportation logistics), representatives from such enterprises were consulted together with experts in information systems design (SAP, Honeywell, ABB, Schneider Electric). These expert evaluations of the budget costs of creating an automated control system are within a range of a $10 \%$ to $25 \%$ ratio of the related construction costs, depending on industry specifics and features of the enterprise.

This ratio can be called an IT-intensity coefficient of the industry and specified for a specific industry, or even for a specific company, based on statistical data or expert opinion.

Of course, the range of expert opinions is very broad. However, taking enterprise creation costs into account, even the lowest estimated cost of creating IT architecture and infrastructure $(10 \%)$ is significant. Should these costs not be considered in calculating the investment costs of creating a new enterprise, the overall project budgets would be significantly underestimated.

Even though the data obtained from this industry feedback is limited, it still strongly supports the relevance of the integrated EA approach in enterprise creation. 
Thus, to forecast the real cost of investment projects of infrastructure-intensive enterprise creation based on the known costs of the material infrastructure, the following formula is proposed:

$$
C=\left(1+c_{I T}\right) \cdot C_{p r}
$$

where $c_{I T}$ is the IT-intensity coefficient, dependent on the industry. According to the industry feedback received in this study, this coefficient can vary from 0.1 to 0.25 ; and where $c_{I T}$ is the estimated costs of creating the material infrastructure.

The publicly available data on the cost of large-scale projects of creating infrastructureintensive enterprises in Russia from 2000 to the present (including the development of deposits, construction of mining and processing combined works, logistic hubs, and defense industry facilities) are provided in Table 1 [46].

Table 1. Selected data on project costs of infrastructure-intensive enterprises in Russia since 2000.

\begin{tabular}{ccc}
\hline No. & Facility & Cost, Million EUR \\
\hline 1 & Baltic NPP & 3200 \\
2 & Fourth generating unit at Beloyarsk Nuclear Power & 2200 \\
3 & Station & \\
4 & Third generating unit at Berezovskaya Thermal Power & 700 \\
5 & Station & 600 \\
6 & Birst phase of the Budyonnovskiy gas chemical facility & 2000 \\
7 & Vancor field & 5370 \\
8 & Gremyachinskiy mining and concentrating mill & 1670 \\
9 & Yamal LNG plant & 23,570 \\
10 & Fourth generating unit at Kalinin NPP & 1400 \\
11 & Zapsibneftekhim petrochemical facility & 8285 \\
12 & JSC Taneco, a group of petroleum processing and & 3357 \\
13 & petrochemical plants & Vostochny Cosmodrome, phase one \\
14 & Kursk NPP-2 & (estimated) 21,000 \\
15 & Prirazlomnaya marine stationary sleet-proof platform & 940 \\
16 & Natalka mining and concentrating mill & 1000 \\
17 & Sakhalin-2 petroleum and gas development & 9570 \\
18 & Ust-Luga port & 4070 \\
19 & Taman' port & 2850 \\
20 & Talakanskoe petroleum and gas condensate field & 3100 \\
\hline
\end{tabular}

\subsection{A Model for Shortening the EA and IT Investment Cycle}

This section proposes an investment and assessment model for shortening the EA and IT investment cycle. An investment cycle, as understood for the purpose of this study, is the sum of the interrelated phases of investments in enterprise creation, including design, creation, and those operational phases from which the ROI is drawn. The investment cycle phases for creating an enterprise physical infrastructure and IT architecture are presented in Table 2, together with the proposed investment indexes and their parameters.

Table 2. Investment cycle phases for creating an enterprise physical infrastructure and information technologies (IT) architecture.

\begin{tabular}{lcc}
\hline Investment Cycle Phases & Index & Notes \\
\hline Enterprise creation & & - \\
\hline (1) $\quad \begin{array}{l}\text { Forming a business idea and a business } \\
\text { concept, R\&D work }\end{array}$ & $t_{1}^{\text {ent }}$ & - \\
\hline (2) Design and survey work & $t_{2}^{\text {ent }}$ & - \\
\hline
\end{tabular}


Table 2. Cont

\begin{tabular}{|c|c|c|c|}
\hline \multicolumn{2}{|c|}{ Investment Cycle Phases } & \multirow{2}{*}{\begin{tabular}{c|} 
Index \\
$t_{3}^{e n t}$
\end{tabular}} & \multirow{2}{*}{$\begin{array}{c}\text { Notes } \\
-\end{array}$} \\
\hline (3) & Completing units of physical facilities & & \\
\hline (4) & Construction and installation (CAI) & $t_{4}^{\text {ent }}$ & - \\
\hline (5) & Pre-commissioning & $t_{5}^{e n t}$ & - \\
\hline (6) & $\begin{array}{l}\text { Operational period for which the } \\
\text { return on investment was ensured }\end{array}$ & $t_{6}^{e n t}$ & - \\
\hline \multicolumn{4}{|c|}{ IT architecture creation } \\
\hline (1) & Developing an IT architecture concept & $t_{1}^{I T}$ & $\begin{array}{l}t_{1}^{I T}=t_{1}^{I T^{\prime}}+t_{1}^{I T^{\prime \prime}}, \text { where } \\
t_{1}^{I T^{\prime}} \text { is the phase duration as to IAS } \\
t_{1}^{I T^{\prime \prime}} \text { is the phase duration as to other subsystems }\end{array}$ \\
\hline (2) & $\begin{array}{l}\text { Elaborating the design assignment for } \\
\text { IT architecture and its subsystems, } \\
\text { engineering processes (EP) for IT } \\
\text { architecture and its subsystems, R\&D } \\
\text { for IT architecture and its subsystems }\end{array}$ & $t_{2}^{I T}$ & $\begin{array}{l}t_{2}^{I T}=t_{2}^{I T^{\prime}}+t_{2}^{I T^{\prime \prime}}, \text { where } \\
t_{2}^{I T^{\prime}} \text { is the phase duration as to IAS } \\
t_{2}^{I T^{\prime \prime}} \text { is the phase duration as to other subsystems }\end{array}$ \\
\hline (3) & $\begin{array}{l}\text { Developing information systems } \\
\text { (programming) }\end{array}$ & $t_{3}^{I T}$ & $\begin{array}{l}t_{3}^{I T}=t_{3}^{I T^{\prime}}+t_{3}^{I T^{\prime \prime}}, \text { where } \\
t_{3}^{I T^{\prime}} \text { is the phase duration as to IAS } \\
t_{3}^{I T^{\prime \prime}} \text { is the phase duration as to other subsystems }\end{array}$ \\
\hline (4) & $\begin{array}{l}\text { Completing units of the physical } \\
\text { facilities of IT architecture }\end{array}$ & $t_{4}^{I T}$ & $\begin{array}{l}t_{4}^{I T}=t_{4}^{I T^{\prime}}+t_{4}^{I T^{\prime \prime}}, \text { where } \\
t_{4}^{I T^{\prime}} \text { is the phase duration as to IAS } \\
t_{4}^{I T^{\prime \prime}} \text { is the phase duration as to other subsystems }\end{array}$ \\
\hline (5) & IT architecture tests and refining & $t_{5}^{I T}$ & $\begin{array}{l}t_{5}^{I T}=t_{5}^{I T^{\prime}}+t_{5}^{I T^{\prime}}, \text { where } \\
t_{5}^{I T^{\prime}} \text { is the phase duration as to IAS } \\
t_{5}^{I T^{\prime \prime}} \text { is the phase duration for other subsystems }\end{array}$ \\
\hline (6) & $\begin{array}{l}\text { Operational period for which the } \\
\text { return on investment was ensured }\end{array}$ & $t_{6}^{I T}$ & $\begin{array}{l}t_{6}^{I T}=t_{6}^{I T^{\prime}}+t_{6}^{I T^{\prime \prime}}, \text { where } \\
t_{6}^{I T^{\prime}} \text { is the phase duration as to IAS } \\
t_{6}^{I T^{\prime \prime}} \text { is the phase duration as to other subsystems }\end{array}$ \\
\hline
\end{tabular}

IAS: Industrial Automation Systems.

(1) $T^{\text {ent }}$ is the cycle for creating the physical facilities of the enterprise:

$$
T^{e n t}=t_{1}^{e n t}+t_{2}^{e n t}+t_{3}^{e n t}+t_{4}^{e n t}+t_{5}^{e n t}+t_{6}^{e n t}=\sum_{i=1}^{6} t_{i}^{e n t}
$$

and

(2) $T^{I T}$ is the cycle for creating the enterprise IT architecture:

$$
T^{I T}=t_{1}^{I T}+t_{2}^{I T}+t_{3}^{I T}+t_{4}^{I T}+t_{5}^{I T}+t_{6}^{I T}=\sum_{j=1}^{6} t_{j}^{I T} .
$$

The most efficient variant for designing and developing IT architecture items as part of the infrastructure-intensive enterprise implies that the "design and survey work" phase involves specifying the requirements for industrial automation systems (IAS) and elaborating the initial steps for developing the IAS architecture.

In this case, phases one to six of the investment cycle for creating the IT architecture of the IAS are implemented in phases two to six of the investment cycle for creating the enterprise physical facilities. This being said, the subsequent creation of other IT architecture subsystems will require investing time and monies on integrating the earlier created IAS and the new subsystems. 
In this case, the full investment cycle of automated enterprise creation (Figure 1) is calculated as follows:

$$
T_{1}=t_{1}^{e n t}+\sum_{i=2}^{6} \max \left(t_{i}^{e n t} ; t_{i}^{I T^{\prime}}\right)+\sum_{j=2}^{6} t_{j}^{I T^{\prime \prime}}+t^{i n t},
$$

where $t^{\text {int }}$ is the duration for integrating IAS and other subsystems.

Enterprise facilities creation:

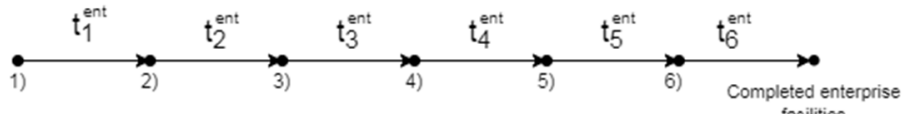

IT creation

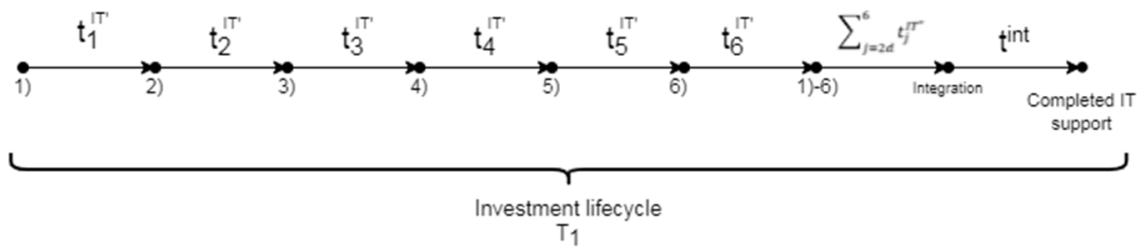

Figure 1. Investment cycle $T_{1}$.

When the objects of the enterprise architecture are developed in a coordinated and synchronized manner, the physical and IT infrastructures are designed and created in parallel and the general creation cycle of the enterprise is given by (Figure 2)

$$
T_{2}=\sum_{i=1}^{6} \max \left(t_{i}^{e n t} ; t_{i}^{I T}\right) .
$$

\section{Enterprise facilities creation}

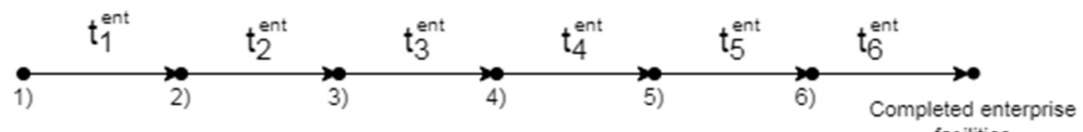

$$
\text { facilities }
$$

\section{IT creation}

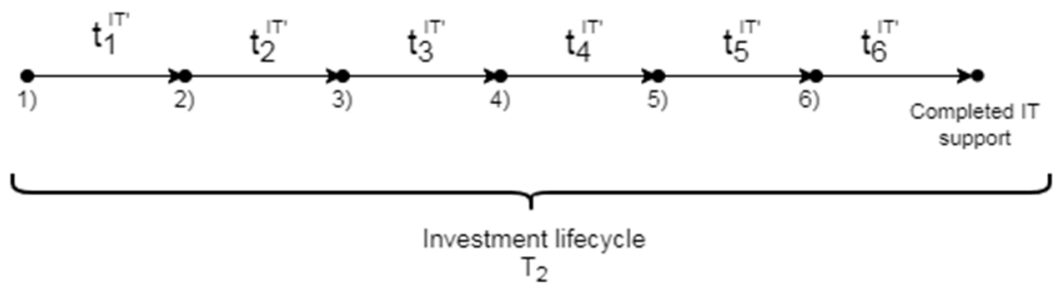

Figure 2. Investment cycle $T_{2}$.

It is clear that $T_{2}<T_{1}$.

In particular, the proposed approach to calculating the efficiency of applying the architectural approach to designing and developing IT architecture for infrastructureintensive enterprises clearly shows the effect of shortening the investment cycle through the synchronized and coordinated development of IT and process architectures. Such calculations should also be relevant for non-infrastructure-intensive enterprises as well, though with a not so vivid effect. 


\subsection{Quantitative Operationalization of the Investment Models for the EA Software Components}

In practice, operationalizing these investment models on real life projects requires adequate quantitative measures, measurement tools, and measurement models for the various aspects of the EA and IT architectures:

On the one hand:

- The measures and measuring instruments for the physical infrastructure and the hardware components of the IT infrastructure must not only be available but also quite mature. All the measures of the physical components must be based on a universally accepted and well-described international system of units (IS), all of which have been verified extensively based on widely accepted criteria defined in the metrology domain [47];

- The fundamental concepts and models for measuring these costs must be based upon the widely accepted accounting bodies of knowledge.

On the other hand, the measures and measuring instruments for the software components of the IT infrastructures are much less mature, less frequently adopted, and some badly designed to the point of being mathematically invalid [48]. Furthermore, a number of the EA measures proposed in the IT domain fail to meet a large number of metrology criteria making them poor candidates for quantitatively operationalizing the software items of the investment models proposed in Equations (1)-(8) [49-51].

The above notwithstanding, a metrology-strong measurement design for quantifying the software components of IT infrastructures has been identified [50,51], based on the COSMIC method from the Common Software Measurement International Consortium [52], and its use illustrated in an EA context. The COSMIC-ISO 19761 standard is only the second generation of international standards for the measurement of the functional size of software applicable to various layers of software within an IT architecture.

This COSMIC method allows the measurement of the functional size of a software suite through the business and engineering functionalities implemented in program code at various levels within an IT architecture. These COSMIC measurement units are independent of the programming and development technologies and can therefore be used to normalize all other technology-dependent indicators through the size of the related business and engineering functions.

The software size measured in this manner can be converted to units of labor intensity and, therefore, can be used to normalize the cost factors incurred in developing and maintaining software functions. Measurements of the functional size of any software can also be used for comparing various IT solutions with each other, planning and tracking the progress of an IT project, and also for estimating the effort spent on IT solution development projects. The software functional size is usually the main factor for estimating the scope of software development projects [53], and therefore the development costs are used to operationalize the investment models proposed in this study.

This COSMIC method has gained popularity among IT developers and is an efficient candidate for analyzing software suite development costs and using such information to employ the investment models.

Furthermore, the COSMIC Group is proposing a number of COSMIC-related approximation techniques for early software sizing, including approximation techniques applicable in the context of EA and IT planning, making this specifically relevant for use in EA investment models targeting the software components of IT infrastructures [54,55].

\section{Discussion}

\subsection{Discussion: Investment Models for IT and EA Projects}

The focus of the research presented in the paper is on the 'investment models' for IT and EA projects; the quality or performance evaluation of IT and EA are beyond the scope of the paper.

The investment models proposed in this paper have certain limitations: 
- They are mostly focused on the needs of infrastructure-intensive enterprises in the context of the ongoing digital transformation. For those enterprises where physical facilities do not play such an essential role in producing the key products (i.e., for operating key processes), parallel designing and implementation of physical infrastructure and IT cannot be the sensitive issue and the complex automation approach using EA concepts can show less illustrative effect. However, this effect will still occur. Further work is needed to explore how to tailor these models to other types of enterprises, from small to much larger ones. There is also the issue of scalability to various business and engineering domains, from a small to very large organizational scale;

- The investment models proposed here are tackling more in regards to the situation of greenfield establishment of the enterprise and its IT architecture, while in practice reengineering and modernization projects occur more often. Models (6) and (7) need a certain adoption to the reengineering or modernization projects situation: in this context, the unnecessary summands should be eliminated from the formulas.

Moreover, since these models have been initially designed for a forecasting context of investment (that is within an 'a priori' context) further research work will be needed to operationalize them for the assessment of EA projects once completed, and for efficiency comparison of completed projects developed in a variety of contexts, that is for an 'a posteriori' context. Additional work is also required to collect data in a posteriori contexts in order to develop fact-based (e.g., a posteriori) ratios (and related phase-based ratios) which could then be used:

- A posteriori to calculate the IT intensity index for various industries and assess development projects performance;

- A priori by transforming them into scalability ratios to be used a priori in investment models.

\subsection{Discussion: EA and IT to Motivate Open Innovations}

In recent years, many industries and companies have been rethinking their business models towards an open innovation model. The Covid-19 crisis has become another factor accelerating this process $[56,57]$. Consideration of enterprise architecture in the context of open innovation is possible in two ways:

- Enterprise architecture as a model of the enterprise, which gives an idea of its structure and the relationship between elements and the external environment, is a mandatory prerequisite for enterprises, following the path of open innovation. As such, the value of the architectural model (and the IT architecture as an integral part of it) is to explicitly describe the architectural areas that are elements of enterprise innovation and are open to external participants in the transfer of knowledge and technology. The architectural model will allow the following: a. correctly and consistently separate the open and closed areas of the enterprise, including the areas of data, knowledge, technology, personnel; b. describe the channels of interaction (including channels of information exchange) of the enterprise with the innovation environment;

- Enterprise architecture and individual architectural solutions (in particular, IT solutions) themselves can be an object of innovation, which can be shared. Architectural models are of particular interest for enterprises within the same industry or related industries. Effective and innovative architectural solutions can be de facto industry standards or best practices for business management.

Enterprise architecture (and IT architecture as a part of it) in both proposed guises in relation to open innovation is a little-studied topic and, according to the authors, is a promising topic for further research. An important issue is the degree of openness of the enterprise in relation to the innovation ecosystem, in particular, openness in the field of IT architecture, and as a consequence-the problem of motivating ecosystem participants to open their developments without fear of losing competitive advantage [58]. Effective 
information and communication support for the innovation process of an enterprise and its environment is an additional factor in favor of investment in IT as part of a comprehensive architectural solution for an innovative enterprise.

\section{Conclusions}

Investments models for information systems and technologies have been a sensitive issue for the academic and professional communities since the time of active process automation. The current study analyzes the issue from the perspective of the following aspects:

- EA elements implementation leads to large re-engineering projects with significant investments, which do not seem attractive in the short term;

- Existing investment models for creating an enterprise and its parts include the costs of creating the physical infrastructure facilities related to the primary activity technology but typically ignore automation-related costs;

- Investment models for EA and IT are especially relevant to enterprises with a complex production infrastructure that requires automatic controls or digital devices for collecting and processing primary data on engineering and production processes.

To address the investment model issue, the study first analyzed the existing research [24-33] concerning forecasting and investment models (e.g., Total Cost of Ownership (TCO), Total Value of Ownership (TVO), Cost Effectiveness Analysis (CEA), business value approach) and highlighted their advantages and limitations. This review revealed that none of the previous methods of investment forecasting and performance assessment for adoption and upgrading of IT architecture and its items [42-44] provided an exhaustive description of the effect of implemented IT solutions.

The key contribution in our paper is that the investment and appraisal models proposed have advantages associated with the ability to calculate the effect of an integrated approach to the implementation of IT solutions aligned with the implementation of the physical infrastructure of the enterprise in terms of investment costs and investment period.

In comparison to the limitations of the models in the literature (listed in Section 4), in terms of quantifying the effect of developing architectural solutions (including IT) as part of the integral EA approach, the investment and assessment models proposed in this study have the following advantages:

- Ability to calculate the effect of the integral approach to adopting IT solutions vs. their patchwork deployment development;

- More precise calculation of investment project costs by considering the cost of IT systems in the costs of integrated architectural solutions;

- Shortening of the investment cycle of developing and implementing architectural solutions, including the physical and IT components;

- Using an international standard of software measurement (e.g., COSMIC-ISO 19761) to operationalize in practice the selected investment model.

These advantages allow the formation of an integral perspective of the characteristics of a project for developing, adopting, and/or upgrading EA and IT infrastructures and their items, and calculating the estimated investment costs of EA development projects, including the IT solution. In addition, they allow optimization of the overall time needed for implementing all of the components of the architectural solution, and comparison of the cost of implementation with or without an EA approach. Together with the classical economic performance indicators of IT projects (e.g., Total Cost of Ownership (TCO), Total Value of Ownership (TVO), Cost Effectiveness Analysis (CEA), business value approach) the investment models proposed in this paper provide a more exhaustive coverage for IT project investment decisions.

This paper has presented a proposal of an 'investment model'. To implement it, an organization would have to deal with the sizing of the items that affect the overall cost of the investment and the time necessary for each stage of the data collection. An example of suggestions for such sizing is presented in previous research from the authors $[48,59]$. 
The proposed models are suitable for practical use when evaluating projects for the implementation of complex architectural solutions, including an IT component. The models are especially relevant for so-called infrastructure-intensive companies, which possess a complex physical infrastructure for running their operational processes (i.e., production, construction, healthcare, and transport companies,) and are open to innovative activities.

The specific attention of further research of the investment models for IT and EA solution assessment would need to focus on collecting data for development examples for models (1)-(7) application; investigating the industry-specific cost structure and intensity of using IT for getting more precise results for the model (3); analyzing the effect of implementing particular digital technologies into the EA.

Author Contributions: Conceptualization, I.V.I.; Investigation, A.S.D.; Methodology, A.I.L. and A.A.; Supervision, I.V.I.; Visualization, A.S.D.; Writing—original draft, A.I.L.; Writing—review \& editing, A.A. All authors have read and agreed to the published version of the manuscript.

Funding: The research is partially funded by the Ministry of Science and Higher Education of the Russian Federation as part of World-class Research Center program: Advanced Digital Technologies (contract No. 075-15-2020-934 dated by 17 November 2020).

Institutional Review Board Statement: Not applicable.

Informed Consent Statement: Not applicable.

Data Availability Statement: Data available in a publicly accessible repository.

Acknowledgments: This paper and the research behind it would not have been possible without the support of our industrial partners (enterprises of Saint Petersburg), who provided us with necessary data and gave their precious feedback on our research ideas, but wished to stay in the shade of the authors.

Conflicts of Interest: The authors declare no conflict of interest. The funders had no role in the design of the study; in the collection, analyses, or interpretation of data; in the writing of the manuscript, or in the decision to publish the results.

\section{References}

1. Kotkova Striteska, M.; Prokop, V. Dynamic innovation strategy model in practice of innovation leaders and followers in CEE countries-a prerequisite for building innovative ecosystems. Sustainability 2020, 12, 3918. [CrossRef]

2. Aldea, A.; Iacob, M.-E.; Wombacher, A.; Hiralal, M.; Franck, T. Enterprise Architecture 4.0-A vision, an approach and software tool support. In Proceedings of the 2018 IEEE 22nd International Enterprise Distributed Object Computing Conference (EDOC), Stockholm, Sweden, 16-19 October 2018; pp. 1-10.

3. Levina, A.I.; Borremans, A.D.; Burmistrov, A.N. Features of enterprise architecture designing of infrastructure-intensive companies. In Innovation Management and Education Excellence through Vision, Proceedings of the 29th Innovation Management and Education Excellence through Vision Conference, Vienna, Austria, 3-4 May 2018; Curran Associates, Inc.: Red Hook, NY, USA, 2020; pp. 4643-4651.

4. Gampfer, F.; Jürgens, A.; Müller, M.; Buchkremer, R. Past, current and future trends in enterprise architecture-A view beyond the horizon. Comput. Ind. 2018, 100, 70-84. [CrossRef]

5. CIO Council. Federal Enterprise Architecture Framework Version 1.1. Available online: http://www.enterprise-architecture. info/Images/Documents/Feàderal\%20EA\%20Framework.pdf (accessed on 1 January 2021).

6. CIO U.S. Department of Defense. The DoDAF Architecture Framework Version 2.02. Available online: https:// dodcio.defense. gov/library/dod-architecture-framework (accessed on 18 March 2020).

7. Dragon1. Enterprise Architecture Benefits. Available online: https://www.dragon1.com/resources/enterprise-architecturebenefits (accessed on 15 May 2020).

8. Lankhorst, M. Enterprise Architecture at Work. Modelling, Communication, Analysis, 3rd ed.; Springer: Berlin, Germany, 2013.

9. Niemi, E. Enterprise Architecture Benefits: Perceptions from Literature and Practice, Proceedings of the 7th IBIMA Conference Internet $\mathcal{E}$ Information Systems in the Digital Age, Brescia, Italy, 14-16 December 2006; IBIMA Publishing: King of Prussia, PA, USA, 2006.

10. Op't Land, M.; Proper, H.A.; Waage, M.; Cloo, J.; Steghuis, C. Enterprise Architecture. Creating Value by Informed Governance; Springer: Berlin/Heidelberg, Germany, 2009.

11. Lapalme, J.; Gerber, A.; Van der Merwe, A.; Zachman, J.; DeVries, M.; Hinkelmann, K. Exploring the future of enterprise architecture: A Zachman perspective. Comput. Ind. 2016, 79, 103-113. [CrossRef]

12. Nardello, M.; Han, S.; Møller, C.; Gøtze, J. Incorporating process and data heterogeneity in enterprise architecture: Extended AMA4EA in an international manufacturing company. Comput. Ind. 2020, 115, 103178. [CrossRef] 
13. Pour, M.J.; Fallah, M.R. How enterprise architecture influences strategic alignment maturity: Structural equation modelling. Int. J. Bus. Excell. 2019, 17, 189. [CrossRef]

14. Shanks, G.; Gloet, M.; Asadi Someh, I.; Frampton, K.; Tamm, T. Achieving benefits with enterprise architecture. J. Strateg. Inf. Syst. 2018, 27, 139-156. [CrossRef]

15. Dewangan, V.M. Godse towards a holistic enterprise innovation performance measurement system. Technovation 2014, 34, 536-545. [CrossRef]

16. Anaya, L.; Dulaimi, M.; Abdallah, S. An investigation into the role of enterprise information systems in enabling business innovation. Bus. Process Manag. J. 2015, 21, 771-790. [CrossRef]

17. Cui, T.R.; Ye, H.; Teo, H.H.; Li, J.Z. Information technology and open innovation: A strategic alignment perspective. Inf. Manag. 2015, 52, 348-358. [CrossRef]

18. Missah, Y.M. Business innovation with enterprise architecture. Int. J. Comput. Appl. 2015, 120, 12-15.

19. Kleis, L.; Chwelos, P.; Ramirez, R.V.; Cockburn, I. Information technology and intangible output: The impact of IT investment on innovation productivity. Inf. Syst. Res. 2012, 23, 42-59. [CrossRef]

20. Yun, J.J.; Zhao, X. Business model innovation through a rectangular compass: From the perspective of open innovation with mechanism design. J. Open Innov. Technol. Mark. Complex. 2020, 6, 131. [CrossRef]

21. Van den Berg, M.; Slot, R.; van Steenbergen, M.; Faasse, P.; van Vliet, H. How enterprise architecture improves the quality of IT investment decisions. J. Syst. Softw. 2019, 152, 134-150. [CrossRef]

22. Liao, Y.-W.; Wang, Y.-M.; Wang, Y.-S.; Tu, Y.-M. Understanding the dynamics between organizational IT investment strategy and market performance: A system dynamics approach. Comput. Ind. 2015, 71, 46-57. [CrossRef]

23. Resolution of the Gosstroy of the Russian Federation of 08/07/2002 N 102; On the Approval of General Instructions for the Use of Reference Books of Reference Prices for Design Work for Construction. Available online: http:/ /www.consultant.ru/document/ cons_doc_LAW_40451/70b18cbc04eb3f0ca8a9c857de67b3147fd71584/ (accessed on 10 January 2021).

24. Ammar, A.; Abran, A.; Abdallah, B. Towards the Adoption of International Standards in Enterprise Architecture Measurement. In Proceedings of the Second International Conference on Data Science, E-Learning and Information Systems, DATA '19, Dubai, United Arab Emirates, 2-5 December 2019; p. 24.

25. Andersen, P.; Carugati, A. Enterprise Architecture Evaluation: A Systematic Literature Review, Proceedings of the 8th Mediterranean Conference on Information Systems, Verona, Italy, 3-5 September 2014; Mola, L., Carugati, A., Kokkinaki, A., Pouloudi, N., Eds.; Association for Information System: Atlanta, GA, USA, 2014.

26. Bonnet, M.J.A. Measuring the Effectiveness of Enterprise Architecture Implementation. Master's Thesis, Delft University of Technology, Delft, The Netherlands, 2009.

27. Gong, Y.; Janssen, M. The value of and myths about enterprise architecture. Int. J. Inf. Manag. 2019, 46, 1-9. [CrossRef]

28. González-Rojas, O.; López, A.; Correal, D. Multilevel complexity measurement in enterprise architecture models. Int. J. Comput. Integr. Manuf. 2017, 30, 1280-1300. [CrossRef]

29. Kurek, E.; Johnson, J.; Mulder, H. Measuring the value of enterprise architecture on IT projects with chaos research. J. Syst. Cybern. Inf. 2017, 15, 13-18.

30. Morganwalp, J.M.; Sage, A.P. Enterprise architecture measures of effectiveness. Int. J. Technol. Policy Manag. 2004, 4, 81-94. [CrossRef]

31. Plessius, H.; Slot, R.; Pruijt, L. On the categorization and measurability of enterprise architecture benefits with the enterprise architecture value framework. In Trends in Enterprise Architecture Research and Practice-Driven Research on Enterprise Transformation; PRET 2012, TEAR 2012; Aier, S., Ekstedt, M., Matthes, F., Proper, E., Sanz, J.L., Eds.; Springer: Berlin/Heidelber, Germany, 2012; Volume 131, pp. 79-92.

32. Rico, D.F. A framework for measuring ROI of enterprise architecture. J. Organ. End User Comput. 2006, 18, 1-12.

33. AlMuhayfith, S.; Shaiti, H. The Impact of enterprise resource planning on business performance: With the discussion on its relationship with open innovation. J. Open Innov. Technol. Mark. Complex. 2020, 6, 87. [CrossRef]

34. Ellram, L.M. Total cost of ownership. Int. J. Phys. Distrib. Logist. Manag. 1995, 25, 4-23. [CrossRef]

35. Uyar, M. A research on total cost of ownership and firm profitability. Res. J. Financ. Account. 2014, 5, 9-16.

36. Gartner Group. IT Glossary. Available online: http:/ / www.gartner.com/it-glossary (accessed on 25 November 2020).

37. Hoffmann, T. TCO: Flawed But Useful. Computerworld. 2002. Available online: https://www.computerworld.com/article/2578 032/it-management/tco--flawed-but-useful.html (accessed on 25 August 2018).

38. Wouters, M.J.F.; Anderson, J.C.; Wynstra, F. The adoption of total cost of ownership for sourcing decisions-A structural equations analysis. Account. Organ. Soc. 2004, 30, 167-191. [CrossRef]

39. Cooper, R. The rise of activity-based costing-part one: What is an activity-based cost system? J. Cost Manag. 1988, 2, 45-54.

40. Cooper, R.S.; Kaplan, R.S. Measure cost right: Make the right decisions. Harv. Bus. Rev. 1988, 66, 96-103.

41. Business Studio. Available online: http://www.businessstudio.ru (accessed on 1 January 2021).

42. Lientz, B.P.; Larssen, L. Manage IT as a Business: How to Achieve Alignment and Add Value to the Company; Butterworth-Heinemann: Oxford, UK, 2004; p. 302.

43. McLaughlin, S. Managing Technology for Business Value; Cambridge Scholars Publishing: Newcastle upon Tyne, UK, 2020 ; p. 565.

44. Harris, M.D.S. The Business Value of Software; CRC Press/Auerbach Publications: Boca Raton, FL, USA, 2018 ; p. 239.

45. Moro-Visconti, R. The Valuation of Digital Intangibles; Palgrave Macmillan: Cham, Switzerland, 2020. 
46. Ruexpert. Large-Scale Russian Projects [Krupnyye Rossiyskiy Proyekty]. Available online: https://ruxpert.ru/\%D0\%9A\%D1\%8 0\%D1\%83\%D0\%BF\%D0\%BD\%D1\%8B\%D0\%B5_\%D1\%80\%D0\%BE\%D1\%81\%D1\%81\%D0\%B8\%D0\%B9\%D1\%81\%D0\%BA\% D0\%B8\%D0\%B5_\%D0\%BF\%D1\%80\%D0\%BE\%D0\%B5\%D0\%BA\%D1\%82\%D1\%8B (accessed on 12 June 2020).

47. International Vocabulary of Metrology-Basic and General Concepts and Associated Terms (VIM); ISO/IEC Guide 99; International Organization for Standardization-ISO: Geneva, Switzerland, 2007.

48. Abran, A. Software Metrics and Software Metrology; Wiley \& IEEE-CS Press: Hoboken, NJ, USA, 2010.

49. Ammar, A.; Lapalme, J.; Abran, A. Enterprise Architecture Measurement: A Systematic Mapping Study. In Proceedings of the 4th International Conference on Enterprise Systems: Advances in Enterprise Systems, Melbourne, Australia, 2-3 November 2016; pp. 13-20.

50. Ammar, A. Analysis of Limitations and Metrology Weaknesses of Enterprise Architecture (EA) Measurement Solutions \& Proposal of a COSMIC-Based Approach to EA Measurement. Ph.D. Thesis, Ecole de Technologie Superieure-Université du Québec, Quebec, QC, Canada, 2019.

51. Ammar, A.; Abran, A. Enterprise architecture measurement: An extended systematic mapping study. Int. J. Comput. Sci. Inf. Technol. Adv. Res. 2019, 11, 9-19. [CrossRef]

52. ISO 19761. Software Engineerin -COSMIC: A Functional Size Measurement Method. 2011. Available online: https://www.iso. org/obp/ui/\#iso:std:iso-iec:19761:ed-2:v1:en (accessed on 15 February 2021).

53. Abran, A. Software Project Estimation-The Fundamentals for Providing High Quality Information to Decision Makers; Wiley \& IEEE-CS Press: Hoboken, NJ, USA, 2015.

54. Abran, A.; Vogelezang, F. (Eds.) Early Software Sizing with COSMIC: Practitioners Guide, COSMIC Organization. 2020. Available online: https:/ / cosmic-sizing.org/publications/early-software-sizing-with-cosmic-practitioners-guide/ (accessed on 15 February 2021).

55. Chen, P.S.; Yen, D.C.; Lin, S.-C.; Chou, C.S. Toward an IT investment decision support model for global enterprises. Comput. Stand. Interfaces 2018, 59, 130-140. [CrossRef]

56. Dahlander, L.; Wallin, M. Why Now Is the Time for “Open Innovation”. Harvard Business Review. Available online: https: / / hbr.org/2020/06/why-now-is-the-time-for-open-innovation (accessed on 15 February 2021).

57. Deichmann, D.; Rozentale, I.; Barnhoorn, R. Open Innovation Generates Great Ideas, So Why Aren't Companies Adopting Them? Harvard Business Review. Available online: https:/ /hbr.org/2017/12/open-innovation-generates-great-ideas-so-why-arentcompanies-adopting-them?ab=at_art_art_1x1 (accessed on 15 February 2021).

58. Linåker, J.; Munir, H.; Wnuk, K.; Mols, C.E. Motivating the contributions: An Open Innovation perspective on what to share as Open Source Software. J. Syst. Softw. 2018, 135, 17-36. [CrossRef]

59. Ilin, I.; Levina, A.; Abran, A.; Iliashenko, O. Measurement of Enterprise Architecture (EA) from an IT Perspective: Research Gaps and Measurement Avenues; Part F131936; ACM International Conference Proceeding Series: New York, NY, USA, 2017 ; pp. $232-243$. 